
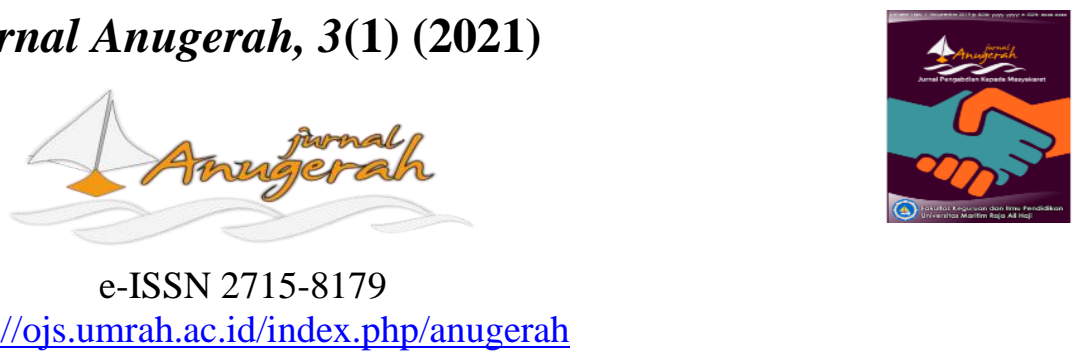

https://ojs.umrah.ac.id/index.php/anugerah

\title{
Pelatihan Software SPSS untuk Menghitung Validitas, Reliabilitas, dan Analisis Butir Soal bagi Mahasiswa Calon Guru di Palembang
}

\author{
Zuli Nuraeni", Ruth Helen Simarmata, Novika Sukmaningthias, Novita Sari \\ Program Studi Pendidikan Matematika, Universitas Sriwijaya \\ Indralaya, OI, Sumatera Selatan 30662, Indonesia \\ *e-mail korespondensi: zulinuraeni@unsri.ac.id
}

Pengiriman: 20 April 2021; Diterima: 23 Mei 2021; Publikasi: 30 Mei 2021

DOI: https://doi.org/10.31629/anugerah.v3i1.3383

\begin{abstract}
Abstrak
Kegiatan ini bertujuan untuk melatih calon guru di wilayah Palembang untuk dapat menghitung validitas, reliabilitas dan analisis butir soal menggunakan software SPSS serta untuk mengetahui respons kepuasan mahasiswa calon guru di wilayah Palembang terhadap kegiatan pelatihan perhitungan validitas, reliabilitas dan analisis butir soal menggunakan software SPSS ini. Kegiatan ini dilakukan dengan metode presentasi dan demonstrasi. Kegiatan ini diikuti oleh 40 mahasiswa calon guru di wilayah Palembang. Hasil dari kegiatan ini adalah peserta pelatihan sudah memahami software SPSS dengan baik untuk menghitung validitas, reliabilitas dan analisis butir soal dilihat dari persentase hasil tugas yaitu $81,58 \%$ tugas sangat tepat, $13,16 \%$ tugas kurang tepat, dan 5,26\% tugas tidak tepat. Kegiatan pengabdian ini juga mendapat respon kepuasan $47,5 \%$ sangat baik, $42,92 \%$ baik, $8,33 \%$ cukup dan $1,25 \%$ kurang. Beberapa hal yang perlu menjadi perhatian dalam kegiatan ini adalah: (1) perlunya menyiapkan bahan dan video tutorial dengan penjelasan yang lebih pelan dan mendetail agar masing-masing peserta dapat mengikuti pelatihan dengan baik, (2) setiap peserta harus sudah menginstall software SPSS ini di komputernya masing-masing, sehingga langsung bisa mempraktikkan sendiri dengan mengikuti instruksi dari narasumber, (3) kegiatan serupa perlu dilaksanakan dengan waktu yang lebih panjang sehingga pelatihan menjadi lebih mendalam.
\end{abstract}

Kata kunci: software SPSS; validitas, reliabilitas, analisis butir soal

\begin{abstract}
This activity aims to train prospective teachers in the Palembang area to be able to calculate validity, reliability, and item analysis using SPSS software and to find out the satisfaction responsses of prospective teacher students in the Palembang area to validity, reliability, and item analysis training activities using this SPSS software. This activity is carried out using presentation and demo methods. This activity was attended by 40 student teacher candidates in the Palembang area. The result of this activity is that the training participants have understood the SPSS software well to calculate validity, reliability and item analysis seen from the percentage of task results, namely $81.58 \%$ of very precise assignments, $13.16 \%$ of inaccurate assignments, and $5.26 \%$ incorrect assignment. This service activity also received a satisfaction responsse of $47.5 \%$ very good, $42.92 \%$ good, $8.33 \%$ sufficient and $1.25 \%$ less. Several things that need attention in this activity are: (1) the need to prepare materials and video tutorials with slower and more detailed explanations so that each participant can take part in the training properly, (2) each participant must install the SPSS software on their each $P C$, so that they can immediately practice themselves by following the instructions from the resource persons, (3) similar activities need to be carried out with a longer time so that the training becomes more indepth.
\end{abstract}


JURNAL ANUGERAH, Mei 2021; Vol. 3(1): 15-23

e-ISSN 2715-8179

Keywords: software SPSS, validity, reliability, item analysis

\section{Pendahuluan}

Kualitas sumber daya manusia sangat ditentukan oleh kualitas pendidikan. Menurut Berdo (2010), pendidikan mempunyai peranan penting dalam pembentukan dan pengembangan sumber daya manusia. Sejalan dengan hal itu, Trihantoro (2019) menyebutkan bahwa tanpa adanya sumber daya manusia yang kompeten dan berdedikasi tinggi maka karyawan suatu organisasi tidak akan dapat memaksimalkan produktivitasnya. Menurut Sihombing \& Sihombing (2011) bahwa kualitas di bidang pendidikan sangat ditentukan oleh kualitas guru sebagai pelaksana tugas. Sehingga guru dituntut untuk profesional dan memiliki kinerja yang tinggi agar bisa meningkatkan kualitas generasi muda bangsa sehingga Indonesia bisa menjadi bangsa yang cerdas dan mampu menghadapi tantangan masa depan.

Menurut Wibowo (2015) salah satu problematika guru lainnya adalah guru lemah dalam mengelola kelasnya (manajemen kelas) dan penguasaan teknologi informasi (IT). Hal ini tentu akan melemahkan kinerja guru baik dalam perencanaan, pelaksanaan dan penilaian pembelajaran. Rendahnya kinerja guru yang paling tampak adalah kinerja guru dalam penilaian diantaranya guru-guru jarang melakukan analisis butir soal (Nuraeni, 2016). Masih banyak guru yang belum mengerti cara menyusun butir tes dan cara menganalisisnya, sehingga butir soal yang diujikan tidak pernah dianalisis dan pada akhirnya guru tidak mengetahui kekurangan dan kelebihan butir soal yang diujikan pada siswa (Rokhayati, 2016).

Kegiatan menganalisis butir soal merupakan salah satu kewajiban bagi setiap guru. Dikatakan kewajiban karena setiap guru pada akhirnya harus dapat memberikan informasi kepada lembaganya ataupun kepada siswa itu sendiri tentang bagaimana dan sejauhmana penguasaan dan kemampuan yang telah dicapai siswa terhadap materi dan keterampilan tentang mata pelajaran yang telah disampaikan. Evaluasi tidak hanya bertumpu pada penilaian hasil belajar, tetapi juga perlu penilaian terhadap hasil masukan dan keluaran akan tetapi juga kualitas proses pembelajaran itu sendiri (Fitrianawati, 2017).

Kenyataan di lapangan menunjukkan bahwa belum semua guru memiliki pengalaman menyusun butir soal karena hal ini terkait dengan sistem penyusunan butir soal yang diserahkan kepada tim tertentu (Mujimin, 2014). Hal ini kian memperparah kualitas butir soal itu sendiri. Meskipun menurut Nuraeni \& Retnowati (2016), proses penilaian yang dilakukan guru sudah cukup baik, dalam perencanaan maupun dalam pelaporan itu sendiri, namun kebanyakan guru tidak melakukan analisis validasi butir soal dan uji reliabilitas instrumen.

Mengingat akan pentingnya analisis butir soal ini, maka dari itu perlu adanya pelatihan kepada mahasiswa calon guru di wilayah Kota Palembang untuk dapat memanfaatkan teknologi software SPSS untuk menghitung validitas butir soal dan reliabilitas instrumen tes karena dalam perkuliahan peserta tidak dibekali mengenai analisis butir soal dengan menggunakan software SPSS. Peserta hanya mengenal program software SPSS untuk mengolah data kuantitatif pada perhitungan statistik menggunakan anava, anacova, manava, mancova dan sebagainya. Analisis butir sendiri, peserta biasa menghitung validitas, reliabilitas dan analisis butir soal secara manual menggunakan rumus Pearson/Alpha Chronbach/ Point Biserial/ KR 20, atau menggunakan program MS Excel.

SPSS (Statistical Packages for Social Science) merupakan aplikasi pengolahan data statistik yang cukup populer di kalangan akademisi. Kelebihan dari software SPSS ini mampu mengakses data dari berbagai macam format data yang tersedia misalnya: Excel, Open Acces, Text bisa langsung dibaca software SPSS untuk dianalisis; software SPSS memberi tampilan data yang lebih informatif, memudahkan pengguna dengan simbol dan ikon yang menarik dan mudah dipahami, software SPSS memberikan informasi lebih akurat dengan memperlakukan missing data secara tepat, yaitu dengan memberi kode alasan mengapa terjadi missing data. Software SPSS melakukan analisis yang sama untuk kelompok-kelompok pengamatan yang 
berbeda secara sekaligus hanya dalam beberapa mouse klik saja; dan software SPSS mampu melakukan analisis statistik yang akurat karena sudah disesuaikan dengan prinsip-prinsip statistika modern yang sudah diintegrasikan oleh para ahli statistik (Yuliardi \& Nuraeni, 2016).

Namun, di samping keunggulan tersebut, software SPSS menuntut pengguna untuk lebih paham tentang command / perintah-perintah yang ada di dalam software SPSS. Banyak mahasiswa sangat kesulitan dalam mengoperasikan software olah data khususnya software SPSS ini (Putra, 2018). Oleh sebab itu, mahasiswa calon guru di wilayah Palembang diajarkan untuk memahami command/ langkah-langkah dalam pengoperasian software SPSS khususnya untuk menghitung validitas, reliabilitas dan analisis butir soal.

Kegiatan pengabdian sebelumnya yang dilakukan oleh Hasyim \& Listiawan (2014) yang berjudul penerapan aplikasi IBM SPSS untuk analisis data bagi pengajar Pondok Hidayatul Mubtadi'in Ngunut Tulungagung demi meningkatkan kualitas pembelajaran dan kreativitas karya ilmiah guru memiliki tujuan agar minat dan antusiasme peserta bagus, meningkatnya pengetahuan dan pemahaman pengajar/guru dalam melakukan analisis data kuantitatif, dan meningkatnya keterampilan dalam mengoperasikan software statistika yaitu SPSS dalam proses analisis data kuantitatif. Kegiatan pengabdian lain yang dilakukan oleh Putra, dkk (2018) yang berjudul Pelatihan pengolahan data penelitian dengan SPSS bagi mahasiswa lintas perguruan tinggi dalam kabupaten Aceh Barat, Provinsi Aceh bertujuan memberikan keterampilan mahasiswa dalam mengoperasikan SPSS dalam rangka penyelesaian tugas akhir mahasiswa. Begitu juga pengabdian mengenai pelatihan pengolahan data menggunakan aplikasi SPSS pada mahasiswa Prodi Manajemen UMKT yang dilakukan oleh Fauziyah \& Karhab (2019) bertujuan melatih mahasiswa dalam mengolah data menggunakan SPSS dan cara membaca hasil serta mengintepretasikan program SPSS.

Berdasarkan beberapa kegiatan pengabdian terdahulu, belum ada pengabdian pada masyarakat yang melakukan pelatihan mengenai validitas, reliabilitas dan analisis butir menggunakan software SPSS terutama kepada mahasiswa calon guru. Oleh karena itu, tujuan pengabdian ini dimaksudkan untuk (1) melatih mahasiswa calon guru di wilayah Palembang untuk menghitung validitas, reliabilitas dan analisis butir soal menggunakan software SPSS (2) mengetahui respons kepuasan mahasiswa calon guru di wilayah Palembang terhadap kegiatan pelatihan perhitungan validitas, reliabilitas dan analisis butir soal menggunakan software SPSS ini.

\section{Metode}

Khalayak sasaran dalam pengabdian ini adalah 40 mahasiswa calon guru di wilayah Palembang. Sebelumnya peserta diberikan sebuah data hasil uji coba soal tes objektif yang dibuat oleh mahasiswa pendidikan matematika UNSRI kelas Indralaya sejumlah 33 soal yang diujicobakan pada kelas VIII yaitu sebanyak 27 siswa. Model pelaksanaan kegiatan kepada masyarakat ini adalah model pelatihan untuk meningkatkan kemampuan menganalisis butir soal menggunakan software SPSS. Kegiatan dilaksanakan secara daring melalui zoom meeting, google classroom dan grup WhatsApp.

Pelatihan ini menggunakan metode presentasi dan demonstrasi serta menggunakan juga bahan materi yaitu Buku Pedoman Penggunaan software SPSS yang disusun oleh tim pengabdian. Peserta menyimak dan mendengarkan penjelasan dan demonstrasi cara menghitung validitas, reliabilitas dan analisis butir dari narasumber kemudian peserta mempraktikannya dengan menghitung validitas, reliabilitas dan analisis butir soal yang telah diberikan datanya. Soal yang diujicobakan adalah soal tes objektif matematika kelas VIII SMP yang sebelumnya sudah divalidasi secara kualitatif dengan cara one to one, dan expert judgement.

Secara umum, kegiatan yang dilakukan adalah (1) menyusun Buku Pedoman Penggunaan software SPSS untuk statistika, (2) memberikan pelatihan software SPSS untuk menghitung validitas, reliabilitas, dan analisis butir soal melalui Zoom meeting (3) memberikan pendampingan dan bimbingan tugas penghitungan validitas, reliabilitas dan analisis butir soal menggunakan software SPSS melalui Google classroom dan grup WhatsApp bagi peserta yang mengalami kesulitan, (4) menyusun angket respons kepuasan terhadap kegiatan 
JURNAL ANUGERAH, Mei 2021; Vol. 3(1): 15-23

e-ISSN 2715-8179

pelatihan software SPSS untuk menghitung validitas, reliabilitas, dan analisis butir soal, mengumpulkan data dan menganalisis hasil angketnya.

\section{Hasil dan Pembahasan}

Pelaksanaan kegiatan pengabdian kepada masayarakat ini dimulai dari tahap persiapan pelatihan, yaitu melakukan koordinasi dengan tim dan menyosialisasikan kegiatan ini kepada mahasiswa calon guru yang sudah berminat. Koordinasi dilakukan secara intens, mulai dari tanggal pasti pelaksanaan, persiapan alat-alat pendukung kegiatan, serta tata cara pelaksaanaan kegiatan ini yang dilakukan secara daring. Untuk kepentingan pelaksanaan kegiatan ini, tim menyusun buku pedoman penggunaan software SPSS selama kurang lebih 1 bulan. Buku pedoman penggunaan software SPSS ini digunakan sebagai panduan peserta dalam menganalisis data menggunakan software SPSS terutama menghitung validitas, reliabilitas dan analisis butir soal. Buku Panduan ini dapat diunduh di Google Classroom, dan peserta bisa mengunduhnya agar dapat menjadi panduan ketika peserta mengerjakan tugas untuk menghitung validitas, reliabilitas dan analisis butir soal. Buku Pedoman ini terbagi menjadi 4 bagian yaitu pengenalan software SPSS, teknik menginput data, menguji instrumen (validitas dan relibilitas) dan cara mengintepretasi data di Output software SPSS.

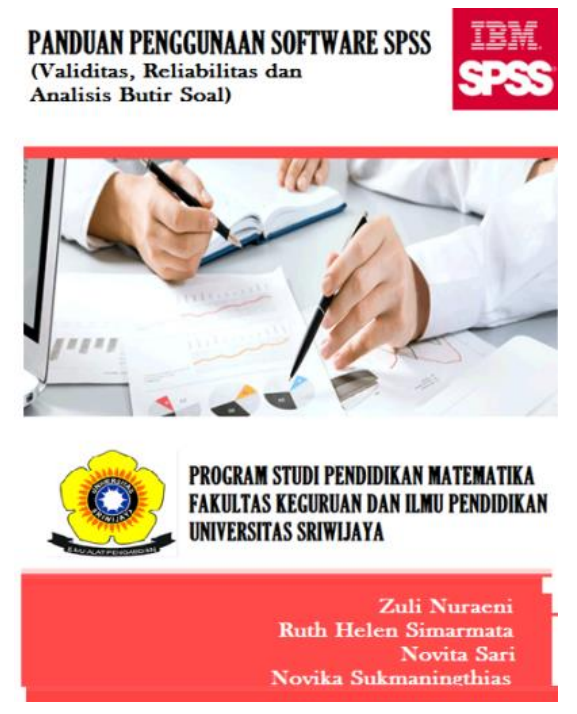

Gambar 1. Cover buku panduan pengunaan software SPSS untuk validitas, reliabitas dan analisis butir soal

Kegiatan pelatihan software SPSS untuk menghitung validitas, reliabilitas, dan analisis butir soal dilaksanakan secara daring melalui zoom meeting pada tanggal 15 Maret 2021 yang diikuti oleh 40 mahasiswa calon guru di Wilayah Palembang yaitu mahasiswa FKIP Universitas Sriwijaya dari beberapa prodi berbeda. Terdapat 2 narasumber utama yang bertugas sebagai pemateri dan asisten dalam pelaksanaan pelatihan, yaitu Ibu Zuli Nuraeni, S.Pd., M.Pd. yang merupakan dosen mata kuliah evaluasi pembelajaran dan Ibu Ruth Helen Simarmata, S.Pd., M.Pd., M.PMat. yang merupakan ahli di bidang stastistik dan teknologi pada Software SPSS.

Kegiatan pengabdian diawali dengan pembukaan dan doa pada pukul 15.00 WIB, kemudian dilanjutkan dengan pemaparan materi oleh narasumber pertama yaitu Ibu Zuli Nuraeni, S.Pd., M.Pd. yang memaparkan tentang hakikat validitas, reliabitas dan analisis butir selama 30 menit. Kemudian dilanjutkan pemaparan materi kedua Ibu Ruth Helen Simarmata, S.Pd., M.Pd., M.PMat. yang menyampaikan Demonstrasi dan teknik validitas, reliabitas dan analisis butir menggunakan Software SPSS selama 30 menit. Dalam menyampaikan materi, narasumber juga menyiapkan presentasi dalam bentuk slide dan video tutorial 
yang juga diunggah dalam Google Classroom. Setelah pemaparan materi kemudian dilanjutkan dengan tanya jawab selama 45 menit dan diakhiri dengan penutupan.

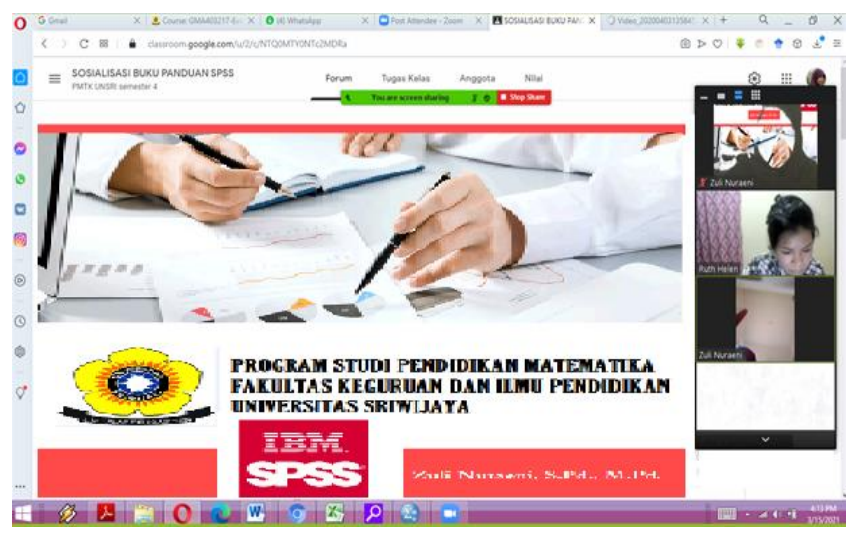

Gambar 2. Pelatihan dilakukan secara daring melalui zoom meeting

Demonstrasi yang dilakukan oleh narasumber kedua yaitu demonstrasi menggunakan Software SPSS dalam menghitung validitas, reliabilitas dan analisis butir soal. Demonstrasi dimulai dengan menunjukkan cara membuka Software SPSS, membuat kolom di software SPSS pada Variable View, cara menginput data di Data View, kemudian dilanjutkan dengan cara menghitung validitas, reliabilitas dan analisis butir soal menggunakan kolom Analyze dan mengintepretasikan Output hasil perhitungan software SPSS tersebut.

Peserta menyimak dan mendengarkan penjelasan yang diberikan oleh narasumber. Peserta yang sedang membuka software SPSS di laptop atau notebooknya juga dapat sekaligus mempraktikkannya mengikuti langkah-langkah yang didemonstrasikan oleh narasumber. Secara umum, pelaksanaan kegiatan pengabdian berjalan lancar tanpa gangguan yang signifikan, hanya saja terdapat beberapa peserta yang keluar masuk ruang Zoom meeting dikarenakan gangguan signal. Hal ini terlihat dari jumlah partisipan yang naik turun selama kegaitan.

Sebelum kegiatan pelatihan ini dimulai, peserta telah disarankan untuk menginstall software SPSS pada PCnya masing-masing. Supaya peserta dapat langsung mempraktikkan langsung mengikuti instruksi dari narasumber saat demonstrasi menghitung validitas, reliabilitas, dan analisis butir menggunakan software SPSS. Namun masih ada beberapa peserta yang belum menginstall software SPSS pada PCnya sehingga peserta tersebut hanya menyimak penjelasan narasumber tanpa praktik menghitung validitas, reliabilitas, dan analisis butir menggunakan software SPSS.

Pada pelatihan ini disediakan sesi tanya jawab yang berlangsung 2 arah. Ketika peserta merasa bingung dengan materi penghitungan validitas, reliabilitas, dan analisis butir atau menemukan kendala selama menjalankan software SPSS, peserta bisa langsung menanyakan kepada narasumber dengan klik raise hand untuk bertanya langsung atau menuliskan pertanyaan di kolom chat. Dan narasumber langsung memberikan jawaban dan arahan atas permasalahan yang dihadapi peserta. Selain itu juga sesi tanya jawab ini masih berlanjut pada proses bimbingan pada saat peserta mengerjakan tugas melalui grup WhatsApp. 

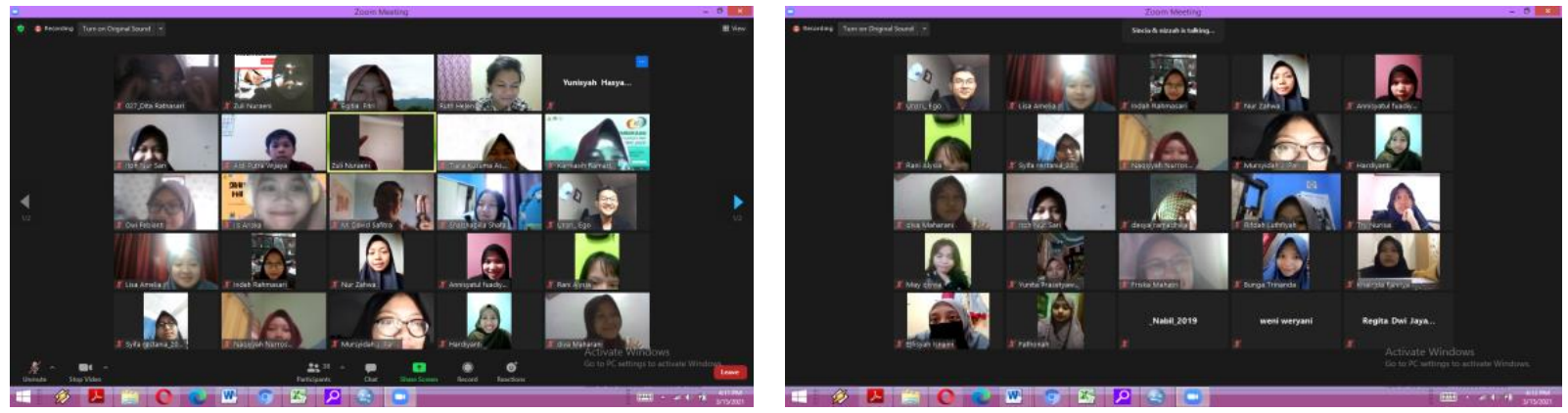

Gambar 3. Sesi tanya jawab

Sebagian besar pertanyaan dari peserta mengenai output hasil perhitungan software SPSS. Peserta masih merasa kesulitan mengintepretasikan Output software SPSS yang memuat banyak informasi data statistik. Pertanyaan lain dari peserta juga bagaimana caranya membuat instrumen soal menjadi valid, reliabel dan memiliki efek potensial. Selain menyimak penyampaian materi dari narasumber, peserta juga diharuskan untuk latihan menghitung validitas butir dan reliabilitas instrument tes dengan menggunakan software SPSS melalui penugasan menghitung validitas, reliabilitas dan analisis butir soal yang sudah diberikan datanya. Data yang diberikan adalah berupa hasil uji coba soal tes soal tes objektif yang dibuat oleh mahasiswa pendidikan matematika UNSRI kelas Indralaya sejumlah 33 soal yang diujicobakan pada kelas VIII yaitu sebanyak 27 siswa. Sehingga peserta bisa memanfaatkan data tersebut untuk latihan menghitung validitas, reliabilitas dan analisis butir soal. Gambar 4 dan 5 adalah contoh hasil kerja peserta pelatihan dengan software SPSS

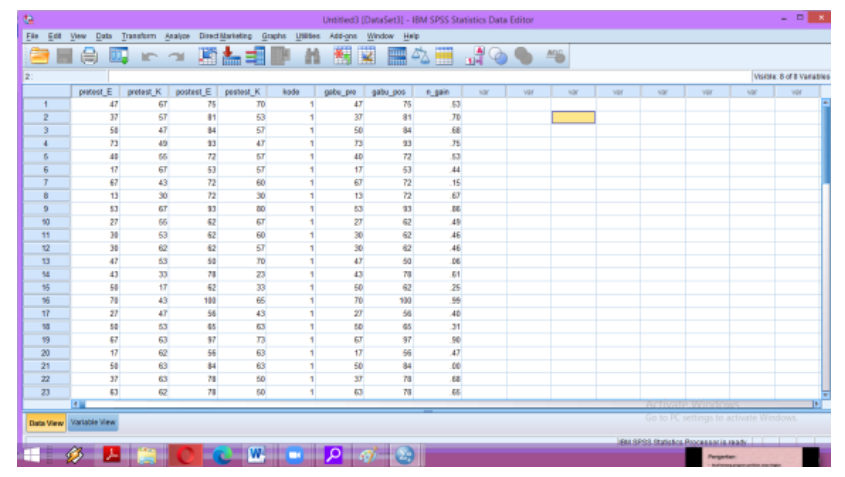

Gambar 4. Tugas analisis peserta

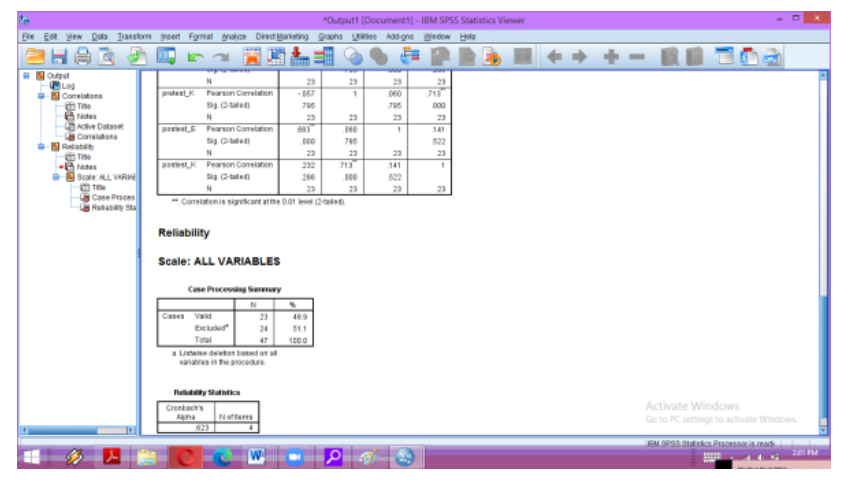

Gambar 5. Hasil output software SPSS tugas peserta 
Peserta diberikan waktu satu pekan untuk mengerjakan tugas menghitung validitas, reliabilitas dan analisis butir soal dengan software SPSS. Selama pengerjaan tugas, tim pengabdian tetap memberikan bimbingan dan pendampingan kepada peserta yang mengalami kesulitan. Bimbingan dan pendampingan dilakukan melalui grup WhatsApp. Setelah itu, peserta dapat mengumpulkan tugasnya melalui google Classroom. Berdasarkan tugas yang terkumpul, dapat terlihat bahwa peserta telah mampu menghitung validitas, reliabilitas dan analisis butir soal dengan software SPSS dan juga bisa mengintepretasikan output software SPSS dengan benar.

Berdasarkan hasil analisis tugas tersebut, sebanyak 38 (95\%) peserta yang mengumpulkan tugas dan 2 peserta tidak mengumpulkan tugas. Dari jumlah peserta yang mengumpulkan tugas, $81,58 \%$ atau sebanyak 31 peserta yang tugasnya tepat artinya peserta sudah mampu menggunakan software SPSS untuk menghitung validitas, reliabilitas dan analisis butir soal dan juga mengintepretasikan output software SPSS. Sebanyak 5 orang atau sebanyak $13,16 \%$ peserta tugasnya kurang tepat karena masih kurang teliti dalam mengintepretasikan output software SPSS. Sedangkan 2 orang 5,26\% peserta tugasnya tidak tepat karena menganalisis butirnya menggunakan perhitungan yang lain, yaitu dengan menggunakan MS Excel.

Selain menyiapkan buku pedoman dan slide presentasi, tim pengabdian juga menyusun angket respons kepuasan peserta mengenai pelaksanaan kegiatan pelatihan. Angket respons kepuasan peserta disusun dengan menggunakan google form yang terdiri atas 6 pertanyaan. Pernyataan-pernyataan didiskusikan dengan seluruh anggota tim yang bertujuan untuk melihat respons kepuasan peserta terhadap kegiatan pengabdian ini meliputi pentingnya materi pelatihan, efektivitas waktu kegiatan, minat, serta keterlibatan seluruh peserta pelatihan. Sesaat sebelum penutupan, narasumber menyebarkan link untuk angket respons kepuasan untuk peserta.

Hasil dari respons kepuasan peserta terhadap kegiatan pelatihan software SPSS untuk menghitung validitas, reliabilitas, dan analisis butir soal adalah sebagai berikut: (1) Indikator materi yang disampaikan pada kegiatan pelatihan mendapat respons sangat baik 50\%, baik 42,5\% dan cukup 7,5\%; (2) Relevansi materi dengan mata kuliah mendapat respons sangat baik 62,5\%, dan baik 37,5\%; (3) Materi yang disampaikan dapat meningkatkan kompetensi mahasiswa sebagai calon guru/peneliti mendapat respons sangat baik 72,5\%, baik 22,5\% dan cukup 5\%; (4) Kejelasan dalam menyampaikan materi mendapat respons sangat baik 42,5\%, baik 50\% dan cukup 7,5\%; (5) Alokasi waktu saat penyampaian materi mendapat respons sangat baik 27,5\%, baik 50\%, cukup 7,5\%, dan kurang 2,5\%; (6) Waktu dalam pengerjaan tugas perhitungan validitas mendapat respons sangat baik 30\%, baik 55\%, cukup 10\%, dan kurang 5\%. Rata-rata respons terhadap keseluruhan item yaitu sebanyak 47,5\% memberikan respons sangat baik, 42,92\% memberikan respons baik, 8,33\% memberikan respons cukup dan 1,25\% memberikan respons kurang.

Temuan pada saat pelaksanaan kegiatan pelatihan pelatihan software SPSS untuk menghitung validitas, reliabilitas, dan analisis butir soal, peserta merasa antusias menyimak materi yang dipaparkan oleh narasumber. Hal ini terlihat dari antusias mereka mencatat beberapa point penting dan meminta narasumber untuk lebih pelan lagi dalam penyampaian materi, serta meminta diulang lagi saat demonstrasi menghitung validitas, reliabilitas dan analisis butir soal. Beberapa peserta juga merasa waktu yang diberikan dalam pelatihan kurang lama dan banyak peserta yang menginginkan waktunya untuk ditambah lagi. Saran dari peserta untuk menambah waktu kegiatan dan mengadakan pelatihan sejenis untuk meningkatkan kompetensi peserta sebagai calon guru dan peneliti.

Hal ini juga sama dialami oleh pengabdian yang dilakukan oleh Putra, dkk (2018) yang mendapatkan temuan bahwa secara keseluruhan peserta memberikan tanggapan sangat puas terhadap terhadap aspek pelaksanaan kegiatan, manfaat kegiatan, modul pelatihan, dan profesionalitas narasumber. Saran dari peserta pelatihan tersebut juga sama agar pelatihan serupa dapat dilaksanakan kembali karena banyak sekali mahasiswa yang belum paham betul mengenai pengelohan data penelitian dengan SPSS. Serta pengabdian yang dilakukan oleh Fauziah \& Karhab (2019) yang memperoleh hasil yaitu meningkatnya pengetahuan, 
JURNAL ANUGERAH, Mei 2021; Vol. 3(1): 15-23

e-ISSN 2715-8179

pemahaman, keterampilan mahasiswa tentang cara mengoperasikan program SPSS, menginput dan memproses data serta membaca output atau menginterpretasikan hasil pengolahan data tersebut.

\section{Kesimpulan}

Melalui kegiatan yang telah dilakukan dapat disimpulkan bahwa peserta pelatihan sudah memahami software SPSS dengan baik untuk menghitung validitas, reliabilitas dan analisis butir soal. Hal ini dibuktikan dengan hasil tugas para peserta yang telah baik dalam menghitung validitas, reliabilitas dan analisis butir soal dengan menggunakan software SPSS yaitu dengan persentase $81,58 \%$ sangat tepat, 13,16\% kurang tepat, dan 5,26\% tidak tepat. Kegiatan pengabdian ini juga mendapat respons kepuasan yang baik dari peserta pelatihan. Sebanyak 47,5\% memberikan respons sangat baik, 42,92\% memberikan respons baik, $8,33 \%$ memberikan respons cukup dan 1,25\% memberikan respons kurang. Artinya kegiatan pengabdian ini mendapatkan respons kepuasan yang baik dari peserta pelatihan software SPSS untuk menghitung validitas, reliabilitas, dan analisis butir soal.

Beberapa hal yang perlu menjadi perhatian dalam kegiatan ini adalah: (1) perlunya menyiapkan bahan dan video tutorial dengan penjelasan yang lebih pelan dan mendetail agar masing-masing peserta dapat mengikuti pelatihan dengan baik dan tidak ada yang tertinggal, (2) setiap peserta harus sudah menginstall software SPSS ini di PCnya masing-masing, sehingga langsung bisa mempraktikkan sendiri dengan mengikuti instruksi dari narasumber, (3) kegiatan serupa perlu dilaksanakan dengan waktu yang lebih panjang sehingga pelatihan menjadi lebih mendalam.

\section{Saran}

Saran yang dapat diberikan adalah agar kegiatan ini dapat dilanjutkan dengan memberikan pelatihan secara berkala atau pelatihan berkelanjutan kepada mahasiswa calon guru ini secara langsung (tatap muka), sehingga dapat menambah pengetahuan dan keterampilan bagi mahasiswa calon guru yang ada di Wilayah Palembang.

\section{Ucapan Terima Kasih}

Penulis mengucapkan terima kasih kepada dosen Pendidikan Matematika Universitas Sriwijaya yang telah memberi dukungan moral, pikiran, waktu dan tenaga terhadap program pengabdian masyarakat ini.

\section{Referensi}

Berdo, S. (2010). Education factor and human resources development: Albania case. Vlorë, Albania: University Pavaresia Press.

Fauziyah, F., \& Karhab, R. S. (2019). Pelatihan pengolahan data menggunakan aplikasi software SPSS. Jurnal Pesut: Pengabdian Untuk Kesejahteraan Umat, 1(2), 129-136.

Fitrianawati, M. (2017). Peran analisis butir soal guna meningkatkan kualitas butir soal, kompetensi guru dan hasil belajar peserta didik. Prosiding Seminar Nasional Pendidikan PGSD UMS \& HDPGSDI Wilayah Jawa (pp. 282-295). Surakarta: UMS.

Hasyim, M., \& Listiawan, T. (2014). Penerapan aplikasi IBM software SPSS untuk analisis data bagi pengajar pondok hidayatul mubtadi'in ngunut tulungagung demi meningkatkan kualitas pembelajaran dan kreativitas karya ilmiah guru. J-Adimas, 2(1), 28-35.

Mujimin (2010). Kompetensi guru dalam menyusun butir soal pada mata pelajaran bahasa jawa di sekolah dasar. Lembaran Ilmu Kependidikan: journal ofeducational research, 39(2), 45-51. 
Nuraeni, Z., \& Retnawati, H. (2016). The post-certification performance of mathematics teachers. The Online Journal of New Horizons in Education, 6(2), 130-142.

Nuraeni, Z. (2016). Self-assessment of teachers of mathematics vocational high school in Yogyakarta city on the performance post-certification. Proceeding ICERE 2016. (pp. 200-205). Yogyakarta: UNY.

Putra, Z., Hasan, I., Budianto, Maulidasari, C.D., \& Chan, S. (2018). Pelatihan pengolahan data penelitian dengan software SPSS bagi mahasiswa lintas perguruan tinggi dalam Kabupaten Aceh Barat Provinsi Aceh. Jurnal ABDIMAS, 3, 1-7.

Rokhayati, R. (2016). Validitas dan reliabilitas tes sumatif buatan guru bahasa indonesia di Kecamatan Limo. Deiksis, 8 (3), $302-315$.

Sihombing, D., \& Sihombing, M. (2011). Analisis korelasi motivasi kerja dengan kinerja guru. Jurnal Darma Agung, J-DA, 1(1), 101-104.

Trihantoro, J. (2019). Pengaruh pelatihan dan motivasi kerja terhadap kinerja karyawan British Council Indonesia di Jakarta. Journal of Economics \& Business, 8(2), 142-149.

Wibowo, C. H. (2015). Problematika profesi guru dan solusinya bagi peningkatan kualitas pendidikan di MTs. Negeri Nguntoronadi Kabupaten Wonogiri. (Tesis tidak diterbitkan). UIN Sunan Kalijaga, Yogyakarta.

Yuliardi, R., \& Nuraeni, Z., (2017). Statiska Penelitian plus tutorial software SPSS. Yogyakarta: Graha Ilmu. 